\title{
Consistency of long sea-level time series in the northern coast of Spain
}

\author{
M. Marcos, D. Gomis, and S. Monserrat \\ Grup d'Oceanografia Interdisciplinar, Instituto Mediterraneo de Estudios Avanzados (UIB-CSIC), Mallorca, Spain \\ E. Álvarez-Fanjul and B. Pérez \\ Área del Medio Físico, Puertos del Estado, Madrid, Spain \\ J. García-Lafuente \\ ETSI Telecomunicación, Departamento de Física Aplicada II, Universidad de Málaga, Malaga, Spain \\ Received 8 June 2004; revised 9 December 2004; accepted 11 January 2005; published 8 March 2005.
}

[1] Sea-level time series recorded at three stations of the northern Spanish coast (Santander, Coruña, and Vigo) are examined with the aim of obtaining reliable interdecadal trends. The records are about 6 decades long, and their consistency is checked by means of an Empirical Orthogonal Function (EOF) analysis. Major benefits of the analysis are the detection of undocumented changes of sea-level reference and the filling of data gaps. For the last decade, the consistency of the trends is also checked against shorter, collocated and nearby records. Results indicate that during the second half of the twentieth century, sea level has been rising at a rate of 2.12, 2.51, and $2.91 \mathrm{~mm} / \mathrm{yr}$ in Santander, Coruña, and Vigo, respectively. Meteorologically induced trends are evaluated from the output of a sea-level numerical model forced by a re-analysis of 44 years of atmospheric data. Results are $-0.44,-0.27$, and $-0.21 \mathrm{~mm} / \mathrm{yr}$, respectively, indicating that in the study region the meteorological forcing acts in the sense of slightly slowing the sea-level rise. On the other hand, sea-level records and the North Atlantic mean temperature exhibit a similar interannual evolution, which points to the thermosteric effect as responsible for the positive trends. Regarding the difference between stations, about a third of it can be attributed to spatial differences in the meteorological forcing. The remaining contribution is attributed to spatial differences in the increase of the ocean heat contents, as suggested by the analysis of SST series during the last decade.

Citation: Marcos, M., D. Gomis, S. Monserrat, E. Álvarez-Fanjul, B. Pérez, and J. García-Lafuente (2005), Consistency of long sealevel time series in the northern coast of Spain, J. Geophys. Res., 110, C03008, doi:10.1029/2004JC002522.

\section{Introduction}

[2] In recent decades, considerable efforts have been devoted to estimate long-term sea-level trends [e.g., Douglas, 1991; Cabanes et al., 2001; Church et al., 2001]. The importance of sea-level variations lies in their impact on ecosystems and habitability in coastal regions, where most of the Earth's population live [Nicholls and Leatherman, 1994]. Global sea-level changes are also directly related to climate change and its social and economical implications. Therefore the knowledge of sea-level trends and their causes is crucial for the design of possible mitigation activities.

[3] Sea-level variations have traditionally been measured by tide gauges located at coastal regions and islands. Available longest records date from the middle of the nineteenth century, although most of the series around the world are less than 60 years long [Woodworth and Player, 2003]. The quality of a tide gauge sea-level record depends on many factors. Observations have to be consistent and independent of the maintenance, change, or repair of the

Copyright 2005 by the American Geophysical Union. 0148-0227/05/2004JC002522 instrument during the entire deployment period. Furthermore, sea-level variations must be coherent among neighboring sites. An accurate vertical reference for the instrument is also of key importance for the estimation of long-term variations. Finally, the presence of large data gaps can eventually mask the actual behavior of the variations.

[4] Nowadays it is commonly accepted that global sea level has been rising at a rate of $1.5-2.0 \mathrm{~mm} / \mathrm{yr}$ during the last century. As an example, Peltier [2001a] obtained a mean rate of $1.84 \mathrm{~mm} / \mathrm{yr}$, with a standard deviation of $0.35 \mathrm{~mm} / \mathrm{yr}$. The spatial distribution of sea-level rise presents some regional differences [Douglas, 2001; Peltier, 2001a]: The average trend has been estimated as $2.19 \mathrm{~mm} / \mathrm{yr}$ in the Western Atlantic Ocean, $1.74 \mathrm{~mm} / \mathrm{yr}$ in the Pacific coast of North America, $1.31 \mathrm{~mm} / \mathrm{yr}$ in the Western Mediterranean, and $1.21 \mathrm{~mm} / \mathrm{yr}$ in the North Eastern Atlantic. Regarding the origin of sea-level rise, thermal expansion of the oceans has been claimed to be a significant contribution to sea-level rise, at least during the last 50 years [Levitus et al., 2000], and it is predicted to continue during the next 50-100 years [Church et al., 2001]. Antonov et al. [2002] estimated the contribution of the thermal expansion in $0.55 \mathrm{~mm} / \mathrm{yr}$. This result is confirmed by the work of Miller and Douglas [2004], 
who pointed out that the dominant contribution is the mass increase primarily due to the melting of continental ice.

[5] During the last decade, satellite altimeters have become an important, additional source of sea-level observations [Parker et al., 1992]. Major advantages of satellite data are the global coverage and the coherence of the observation set. This has allowed the characterization of the spatial pattern of sea-level variations and the estimation of trends at a decadal scale. Cabanes et al. [2001], for instance, inferred a global sea-level rise of $3.2 \pm 0.2 \mathrm{~mm} / \mathrm{yr}$ from TOPEX/Poseidon data spanning the period 19931998, and Nerem [1999] obtained $3.1 \pm 1.3 \mathrm{~mm} / \mathrm{yr}$ for the period 1993-1999. Both works attribute this increase with respect to secular trends to the thermosteric contribution. Willis et al. [2003] have indicated that thermal expansion explains about $60 \%$ of the observed sea-level rate. Therefore the contribution due to a mass increase remains the same as for recent decades (approximately $1.5 \mathrm{~mm} / \mathrm{yr}$ ).

[6] In this context of sea-level trend estimations, the first aim of this work is to examine the consistency of three sealevel series recorded during the last 60 years in the northern Spanish coast. Although other stations with a few decades of data do exist in the region, the three series analyzed here are the ones that a priori better fulfill the requirements for a reliable estimate of interdecadal trends [Douglas, 1997].

[7] In a preliminary check, the last decade of the series will be compared with more recent, collocated records. The study of the long-term consistency will be undertaken in the light of an Empirical Orthogonal Function (EOF) analysis. In addition to separating the main patterns of oscillation, the EOF methodology will be revealed as a useful tool to identify possible errors and to fill the data gaps of the records. Although it cannot be pretended that the applied corrections are able to exactly recover the true series, they will be shown to be crucial for the computation of reliable sea-level trends.

[8] Once the consistency of the series is considered as satisfactory, we will focus on identifying the origin of the obtained sea-level trends, as well as on explaining their spatial variability. First, the effect of local land uplift or subsidence must be removed, in order to obtain absolute sea-level trends. Unfortunately, there is a lack of information on local vertical movements at tide gauge stations. GPS campaigns are scarce in the study region, and the installation of permanent GPS stations has become a usual practice only in recent years (they are nowadays highly recommended for any study aimed at the computation of sea-level trends). Owing to the absence of clear evidences of intense local tectonics, the only correction applied here will be the glacial isostatic adjustment caused by the cycle of glaciation and deglaciation of the past 900,000 years. In particular, we will use the values of the post-glacial rebound (PGR) provided by the ICE4G model [Peltier, 2001b] at places with long sea-level time series. Douglas [1991] presented results for several regions around the world and confirmed a significant improvement in the consistency of computed trends after being corrected with the PGR values.

[9] Particular attention will be devoted to the meteorological forcing, as a major source of variability. The length of the records is of key importance to ensure that annual oscillations and short interannual variability are filtered out from estimated sea-level trends. Decadal modes are more difficult to deal with, and therefore their influence on interdecadal trends must be carefully evaluated. In the study region, the most important source of decadal variability is the North Atlantic Oscillation (NAO). Wakelin et al. [2003] used data from the period 1955-2000 to demonstrate that sea level and the NAO index are significantly correlated over the northwest European continental shelf. This correlation varies from negative values to the south (in northern Spain and Portugal) to positive values to the north (mainly in the Baltic Sea), with absolute values up to 0.8 for wintermean sea level. Also, Woolf et al. [2003] pointed out the strong influence of the NAO in the study region. They computed the sensitivity of sea level to the NAO index and demonstrated that in southern Europe, sea level is lower during NAO-positive years. Values for the northern Spanish coast during the period 1992-2001 range between -20 and $-60 \mathrm{~mm} /$ unit NAO index.

[10] In this work, the meteorological contribution to interdecadal sea-level trends will be quantified based on the output of a sea-level numerical model forced by a reanalysis of 44 years of atmospheric data. These results were obtained in the framework of the HIPOCAS project [Guedes Soares et al., 2002], which will be briefly described later on. More qualitative comparisons between sealevel records and the winter NAO index will also be made, in order to explain the spatial and temporal variability of sea level.

[11] Once the meteorological forcing is determined and removed from sea-level trends, the remaining trend must be attributed to changes in the ocean volume (primarily due to warming) and/or to changes in the total ocean mass (primarily due to the melting of continental ice). At a regional scale, sea-level trends can also be affected by changes in the coastal circulation. Here we will qualitatively check the first contribution by comparing the sea-level records with the evolution of the North Atlantic mean temperature derived by Levitus et al. [2000]. Regarding the spatial pattern, García-Lafuente et al. [2004] established a linear correlation between remotely sensed sea surface temperature (SST) and dynamic height anomaly. The aim was to relate a continuously and globally sampled indicator of thermosteric effects (SST) with a more faithful (but more sparsely sampled) indicator of the thermosteric contribution (dynamic height). Unfortunately, SST has only been routinely available during the last decade, and therefore the estimation of spatially dependent temperature trends will be restricted to this period.

[12] The referred contents are presented as follows. In section 2 we describe the data set and obtain a first estimation of sea-level trends from the raw records. We also carry out a preliminary quality check based on the comparison of the long series with shorter, collocated records. These preliminary results will point out the need for a more detailed consistency analysis, which is presented in section 3. This includes the description of the EOF methodology, as well as the corrections applied onto the raw series as a consequence of the analysis (detection of reference jumps and filling of data gaps). The estimation of decadal and interdecadal trends from the corrected records is presented in section 4, paying special attention to the sensitivity of results with respect to the length of the series. 


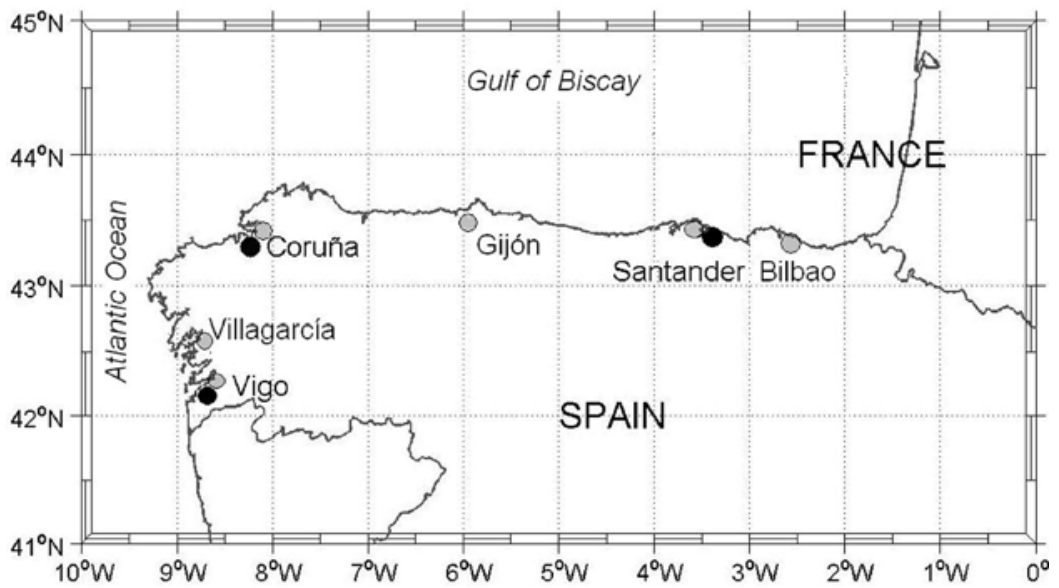

Figure 1. Map of the study region with the location of the IEO (black dots) and PdE (shaded dots) tide gauge stations.

In section 5 we focus on identifying the different physical contributions to sea-level trends. Finally, conclusions are outlined in section 6 .

\section{Data Set and Preliminary Checks}

\subsection{Data Set}

[13] Three tide gauge stations located in the northern coast of Spain and operated by the Instituto Español de Oceanografía (hereinafter IEO) have been recording sealevel variations since 1943. The stations are Santander, Coruña, and Vigo, and their PSMSL (Permanent Service for Mean Sea Level) codes are 200/011, 200/030 and 200/041, respectively (see Figure 1 for their location). The three tide gauges are mechanical float models installed in a well connected to open sea through a small hole, in order to filter high-frequency oscillations.

[14] The initial data sets were hourly sea-level series spanning the 58-year period of 1943-2001. As usual for such long time series, the three records have several gaps, some of them particularly long. For example, the Santander record has gaps of up to 90, 54, and 43 days long; in Coruña, the longest gap is 70 days long; and Vigo has a few gaps of more than 90 days. The percentages of empty or noncomplete days are $4.1 \%$ for Santander, $2.4 \%$ for Coruña, and $1.8 \%$ for Vigo, which is quite acceptable for the computation of reliable trends.

[15] More recently, six additional sea-level stations have been deployed by Puertos del Estado (hereinafter PdE) in the northern Spanish coast (see their location in Figure 1). They are Bilbao (since 1992, PSMSL code 200/006), Santander (since 1992, PSMSL code 200/013), Gijón (since 1997, PSMSL code 200/022), Coruña (since 1992, PSMSL code 200/032), Villagarcía (since 1997, PSMSL code 200/036), and Vigo (since 1992, PSMSL code 200/042). Although these records are useless for the computation of interdecadal trends, they will be useful to check the consistency of the long IEO records during the last decade.

[16] The instruments deployed by PdE are "Sonar Research Development" (SRD) water level monitor gauges that give the distance from the transducer to the water surface by measuring the time elapsed between transmission and reception of an acoustic pulse. The actual sampling frequency of acoustic gauges is very high, but mean values are computed and saved with a sampling interval of $5 \mathrm{~min}$. Also, these series present some data gaps, the longest one being 190 days in the Coruña record. The percentage of empty or noncomplete days (i.e., those with more than 1 hour of missing data) ranges from $1 \%$ in Santander to $17 \%$ in Coruña.

[17] The meteorological contribution to interdecadal sea-level trends has been quantified basing on the results of the HIPOCAS project [Guedes Soares et al., 2002]. A major product of that project was the downscaling (by means of the atmospheric model REMO applied over different European regions) of the historical reanalysis of 44 years (1958-2001) of atmospheric fields carried out by the Climate Diagnostics Centre (CDC-NOAA-CIRES). The obtained sea-level atmospheric pressure matches quite well the observations (correlation $r>0.96$; RMS errors between 1.15 and $2.16 \mathrm{mb}$ ). Differences between hindcast and measured winds are larger, though in the Gulf of Biscay, correlations are still high $(r \sim 0.85-0.90$, $\mathrm{rms} \sim 2 \mathrm{~m} / \mathrm{s}$ ). Wind and sea surface pressure data were used, also in the frame of HIPOCAS project, to force a barotropic version of the HAMburg Shelf Circulation Model (HAMSOM [Álvarez-Fanjul et al., 1997]) over the domain $30^{\circ} \mathrm{N}$ to $47^{\circ} \mathrm{N}$ and $-12^{\circ} \mathrm{E}$ to $35^{\circ} \mathrm{E}$, which includes the Mediterranean Sea and the eastern sector of the North Atlantic Ocean. This version of the code is routinely operated by Puertos del Estado as part of the Nivmar sea-level forecast system [Álvarez-Fanjul et al., 2001]. The comparison between HAMSOM computed and observed residuals is very satisfactory $(r \sim 0.87$ to 0.82 ; RMS errors between 5.2 and $6.4 \mathrm{~cm}$ ).

\subsection{Preliminary Estimation of Sea-Level Trends}

[18] All the original time series were submitted to a daily average, neglecting noncomplete days. A first estimation of the linear trends computed for the IEO series yielded $2.06 \mathrm{~mm} / \mathrm{yr}$ for Santander, $1.46 \mathrm{~mm} / \mathrm{yr}$ for Coruña, and $2.62 \mathrm{~mm} / \mathrm{yr}$ for Vigo (see Table 1). These records have also been routinely analyzed by the PSMSL, but for different periods of the series. This explains the marked dispersion of 
Table 1. Observed and PGR-Corrected Sea-Level Trends Computed for the Raw IEO (Interdecadal and Decadal) and PdE (Decadal) Series ${ }^{\mathrm{a}}$

\begin{tabular}{|c|c|c|c|c|c|}
\hline \multirow[b]{2}{*}{ Station } & \multirow[b]{2}{*}{$\begin{array}{c}\text { Post-Glacial } \\
\text { Rebound }\end{array}$} & \multicolumn{2}{|c|}{$1943-2001$} & \multicolumn{2}{|c|}{$1993-2001$} \\
\hline & & $\begin{array}{l}\text { Relative Sea- } \\
\text { Level Trend }\end{array}$ & $\begin{array}{c}\text { PGR-Corrected Sea- } \\
\text { Level Trend }\end{array}$ & $\begin{array}{l}\text { Relative Sea- } \\
\text { Level Trend }\end{array}$ & $\begin{array}{l}\text { PGR-Corrected } \\
\text { Sea-Level Trend }\end{array}$ \\
\hline IEO-Santander & -0.27 & $2.06 \pm 0.09$ & 2.33 & $10.40 \pm 1.46$ & 10.67 \\
\hline IEO-Coruña & -0.13 & $1.46 \pm 0.09$ & 1.59 & $2.80 \pm 1.53$ & 2.93 \\
\hline IEO-Vigo & -0.22 & $2.62 \pm 0.09$ & 2.84 & $0.51 \pm 1.44$ & 0.73 \\
\hline PdE-Bilbao & -0.33 & & & $5.95 \pm 1.40$ & 6.28 \\
\hline PdE-Santander & -0.27 & & & $5.62 \pm 1.32$ & 5.89 \\
\hline PdE-Coruña & -0.13 & & & $1.50 \pm 1.61$ & 1.63 \\
\hline PdE-Vigo & -0.22 & & & $3.34 \pm 1.56$ & 3.56 \\
\hline
\end{tabular}

results: $-0.25 \mathrm{~mm} / \mathrm{yr}$ for a $36-y e a r$ period of the Santander record, $4.14 \mathrm{~mm} / \mathrm{yr}$ for a 42 -year period of the Coruña record, and $2.68 \mathrm{~mm} / \mathrm{yr}$ for a 55 -year period of the Vigo record.

[19] The confidence of the computed trends was evaluated by means of a bootstrap method [Efron and Tibshirani, 1993]. This method assumes that each time series is just a sample of an unknown distribution of probability. If the distribution was known, mean values and errors could be calculated. The bootstrap method is intended to estimate this distribution by resampling the time series in the following way: If the original record consists of " $\mathrm{m}$ " data pairs of the form [time, sea level], a new sample is constructed by selecting in a random way " $\mathrm{m}$ " pairs allowing repetition. The difference between the original series and the new sample is that some pairs of the first are repeated in the second and, therefore, some original pairs are not included in the new sample. A large number of samples (e.g., $10^{3}$ ) can be obtained and each sample can be analyzed in the same way as the original time series, which results in a distribution of linear trends. The mean value and standard deviation (or the interval including some percentage) of the trend distribution give an estimate for the reliability of the trend computed from the original time series.

[20] For the analyzed stations, mean values given by the bootstrap method differed in less than $0.01 \mathrm{~mm} / \mathrm{yr}$ from those computed for the actual time series. The standard deviations of the distributions were $0.053,0.050$, and $0.052 \mathrm{~mm} / \mathrm{yr}$ for Santander, Coruña, and Vigo, respectively. The interval containing $90 \%$ of the trend distribution was about $\pm 0.085 \mathrm{~mm} / \mathrm{yr}$ for the three series. It then follows that the differences between the three station trends are by far larger than their statistical uncertainty.

[21] A first correction to the obtained relative sea-level trends comes from the effect of the postglacial rebound (PGR). The values given by the ICE4G model [Peltier, $2001 \mathrm{~b}]$ are $-0.27,-0.13$, and $-0.22 \mathrm{~mm} / \mathrm{yr}$ in Santander, Coruña, and Vigo, respectively, the negative values implying land emergence (see Table 1). This correction does not cancel out the differences between the three stations, since the PGR-corrected sea-level trends become 2.33, 1.59, and $2.84 \mathrm{~mm} / \mathrm{yr}$, respectively. An easy explanation would be to attribute these differences to the spatial variability of interdecadal trends, but they seem rather large given the short distance between the stations. In the next sections we will search for the reasons of this lack of consistency.

\subsection{Preliminary Quality Check Against Recent Collocated Records}

[22] Of the six PdE tide gauges deployed along the northern Spanish coast during the 1990s, only those deployed before 1993 will be used in this section (i.e., Bilbao, Santander, Coruña, and Vigo). Decadal trends were computed for both the PdE series and the piece of the IEO records spanning the same period. Results are listed in Table 1, together with the PGR correction and the statistical uncertainty given by the bootstrap method. The first feature worth noting is that the statistical uncertainty of these short series is more than 1 order of magnitude greater than for the long series, as the $90 \%$ confidence intervals range between 1.3 and $1.6 \mathrm{~mm} / \mathrm{yr}$. The reason is the shortness of the records, which is further handicapped by the presence of data gaps.

[23] When comparing collocated stations, the trends of the PdE and IEO Coruña records differ by $1.30 \mathrm{~mm} / \mathrm{yr}$, which is consistent with the statistical uncertainty. Moreover, the monthly averages of both series showed a good agreement for the whole period. For the Vigo records, the trend difference goes up to $2.83 \mathrm{~mm} / \mathrm{yr}$. Although this value is still compatible with the statistical uncertainty, it is close to the limit, and therefore the records were submitted to a closer examination. Monthly averages showed a good agreement between both records until the end of 2000, but significant differences were found within 2001. A direct comparison with nearby records did not allow determination of which of the two records is the anomalous one. This problem will be addressed in the next section by means of an EOF analysis.

[24] Finally, the difference between the two Santander trends can by no means be attributed to the statistical uncertainty. A close examination of the IEO Santander record revealed a generalized anomalous behavior from 1996 onward (which had, in fact, been noticed in advance by IEO). We therefore decided to replace the suspicious piece of the IEO record with the PdE record. The coupling was carried out based on the common period of simultaneous good data (1993-1995), during which the bias between both records was below $1 \mathrm{~cm}$.

\section{Empirical Orthogonal Function Analysis}

[25] Empirical Orthogonal Function (EOF) analysis is a standard tool for the characterization of multidimensional 
data series (see Appendix A for some details on the technique). Here it was applied to the daily time series recorded at Santander, Coruña, and Vigo for the entire period 1943-2001. In the following we first describe the spatial pattern of sea-level variability and then focus on two relevant applications of the EOF methodology: the detection of undocumented changes in the sea-level reference ("jumps" hereinafter), and the filling of data gaps of the series.

\subsection{Spatial Pattern of Sea-Level Variability}

[26] The eigenvectors resulting from the EOF decomposition are represented in Figure 2a. The leading EOF has a rather homogeneous spatial pattern, with values slightly increasing westward. It describes the large-scale variations along the entire coast and accounts for $86.6 \%$ of the total variability. Because of the relatively short distance between stations, this mode can hardly be related to a single physical forcing. Different meteorological forcings, the annual thermosteric cycle, and low-frequency tidal constituents can all contribute to the variability accounted for by this.

[27] The second EOF accounts for $9.5 \%$ of the variability and changes sign between Coruña and Santander (closer to the first than to the second). That is, oscillations associated with this mode have opposite phase in the Atlantic shores and in the Gulf of Biscay, being slightly larger in the second region than in the first. Finally, the third EOF accounts for just $3.5 \%$ of the variance and changes sign between stations, which suggests that it represents rather local phenomena.

[28] In order to test the consistency of the modes, the EOF analysis was also applied to the shorter PdE time series recorded at Bilbao, Santander, Gijón, Coruña, Villagarcía, and Vigo, during the period 1997-2001. Figure 2b shows the spatial distribution of the three leading EOFs. They account for $84.9 \%, 9.2 \%$, and $3.1 \%$ of the variance, respectively, values that are all very close to those obtained for the long IEO time series. Also, the spatial variability is very similar, although the larger number of stations adds some more detail to the patterns. Again, the first mode is nearly constant, with values slightly increasing toward the west. The second EOF reveals that the phase change between the Atlantic and the Gulf of Biscay takes places between Coruña and Gijón. The third mode shows again different behaviors for the Atlantic stations, whereas the three stations located within the Gulf of Biscay (Bilbao, Santander, and Gijón) are more similar. These results indicate that the patterns of the two leading EOFs remain fairly constant in time and do not significantly depend on the number of stations involved in the computations.

\subsection{A First Application of the EOF Analysis: Detection of Reference Jumps}

[29] Any reliable estimation of long-term sea-level trend needs a previous data check for eventual changes in the reference level of the instruments. These are usually associated with the maintenance or substitution of a tide gauge and can have a significant impact on the computed trends. In order to detect possible jumps in the sea-level series, the EOF analysis can be used in the following way.

[30] First, the three records were divided into six 10-year periods (except the first one, which covered from 1943 to 1950, and the last one, which covered from 1990 to
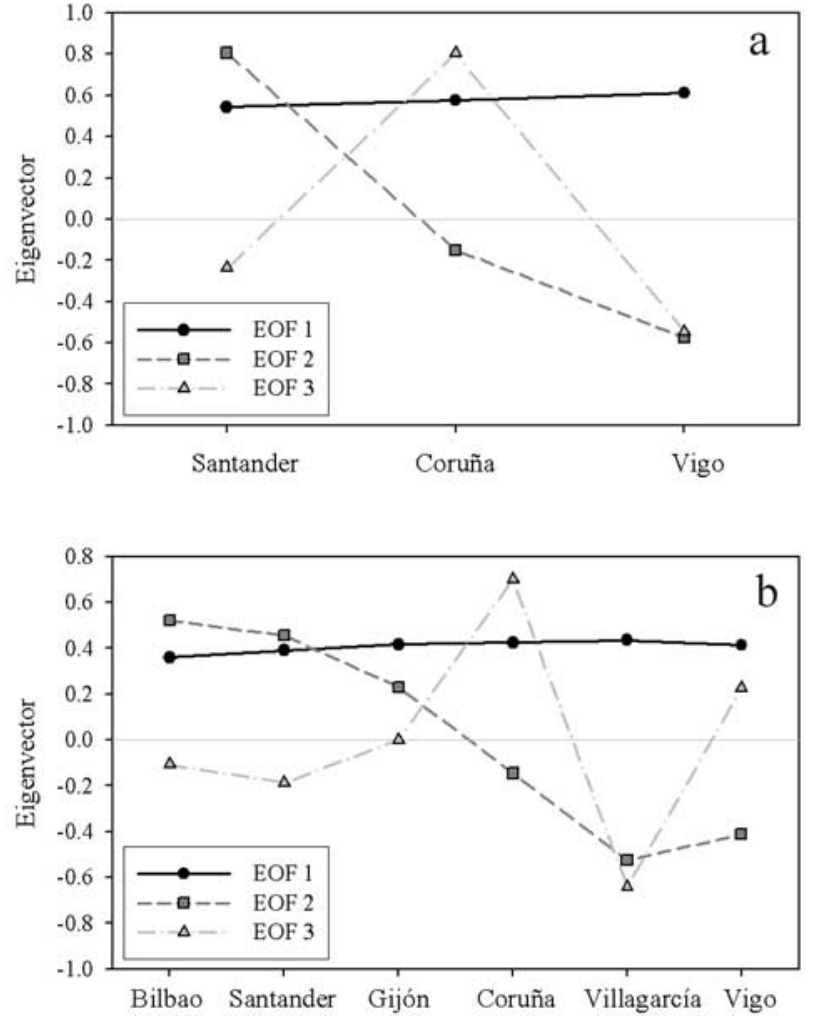

Figure 2. Components of the eigenvectors computed for (a) the long IEO series (1943-2001) NS (b) the shorter PdE series (for the period 1997-2001).

2001). Each of these intervals was then examined as follows: (1) Eigenvectors were computed using all the other intervals as input data, and (2) each of the three station records was then "predicted" using the two leading EOFs and the other two records of the same interval. The reason for using only two EOFs is that it produced slightly better results than using three (as revealed by a test presented in the next section), which is a further indication that the third EOF reflects local phenomena that cannot be extrapolated from one station to the others. Moreover, the two leading EOFs obtained for the different time intervals were very similar, and therefore no discontinuity between intervals was observed in the predictions.

[31] For each station, the prediction was plotted against actual observations and compared. The basis for the detection of jumps is as follows: If, within a given interval, there were a jump in one of the stations, the prediction for that station would not reproduce it. The reason is that predictions are obtained from eigenvectors computed using no data from the wrong interval, and from the other station records of the same interval, which are assumed to be correct. As a consequence, the presence of a jump in the original record should show up as a jump in the differences between data and prediction. Moreover, a jump at a given station would also contaminate the prediction for the other stations within the analyzed interval, resulting in jumps of opposite sign in the differences between data and prediction. Finally, a jump could even contaminate the EOFs used to predict the other 10-year intervals, though to a lesser extent, since only one out of five intervals would have such an 

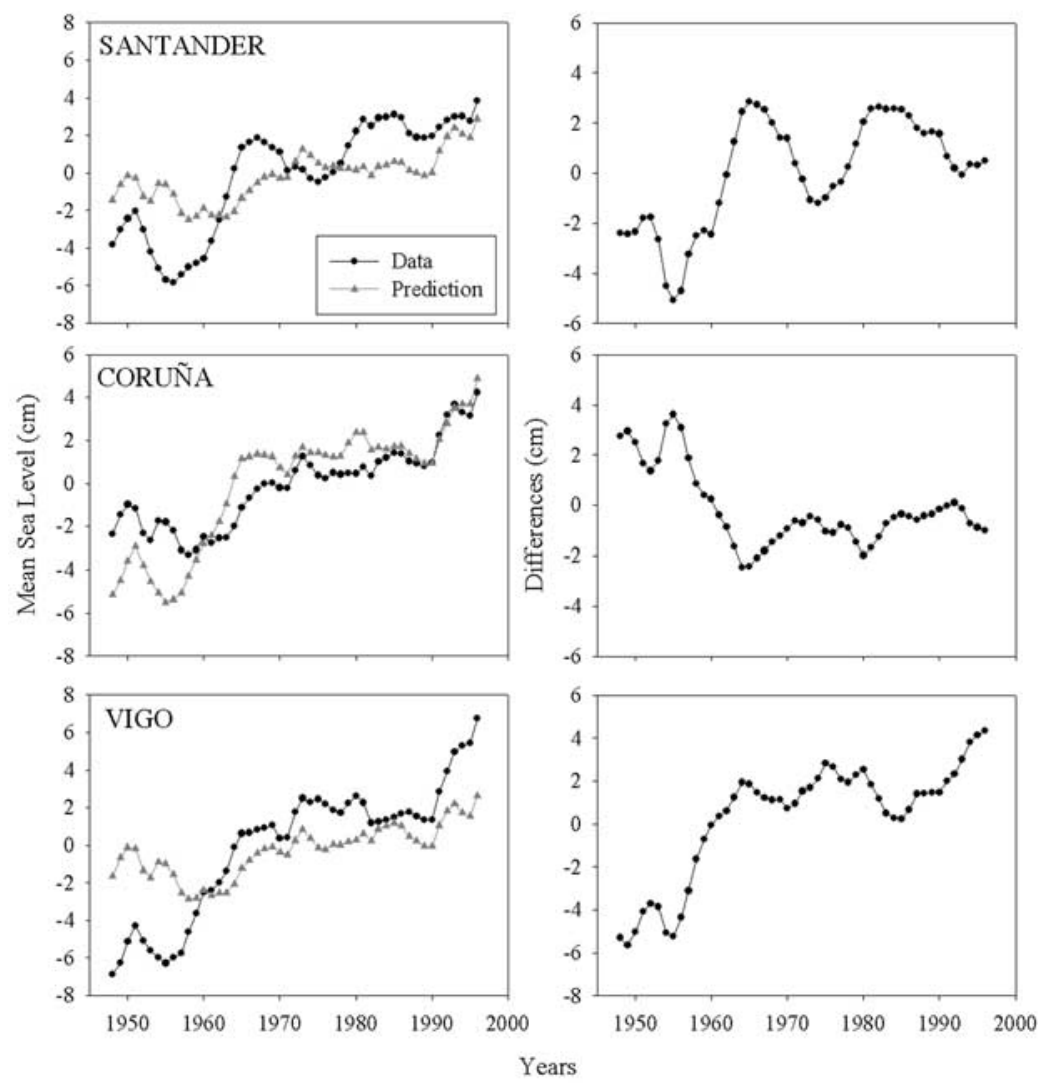

Figure 3. (left) Ten-year moving average of observed (black line) and EOF predicted (shaded line) sea level for the IEO long series. (right) Differences between the (averaged) observed and predicted records.

anomaly. This procedure obviously assumes that jumps are the exception, not the rule. Otherwise, all eigenvector sets could be contaminated and the identification of jumps would become almost impossible.

[32] In practice, even the detection of a single jump is not straightforward from the raw difference records, due to the presence of high-frequency oscillations. For a better detection, both the observed and predicted records were submitted to a 10-year moving average prior to the comparison. Results are shown in Figure 3; the most apparent feature is a jump in the differences of the three stations between 1955 and 1965 (right panels), which suggests the presence of a jump in one of the stations during these years. This coincides with a marked increase in sea level observed at the three stations (left panels). However, while in Santander and Vigo the increase is about $7 \mathrm{~cm}$, it is $3 \mathrm{~cm}$ in Coruña. Moreover, the sign of the jump in the difference record of Coruna is opposite to those observed in Santander and Vigo. All these features are consistent with the existence of a jump in the reference of sea level recorded in Coruña.

[33] When examining the Coruña record, a single data gap of 70 days starting in June 1963 was detected between 1955 and 1965. Because this interruption was a likely candidate for the jump, we compared observations and prediction during a period before (year 1945) and after (year 1980) the hypothesized jump (Figure 4). For both periods, actual sea-level variations are fairly well reproduced by the prediction. However, while for the period before 1963 the prediction is clearly a few centimeters below the observations, for the period after 1963 both records are very similar. This feature (also apparent in Figure 3) suggests that the piece of record to be corrected is that obtained before 1963 .

[34] The magnitude of the vertical jump was estimated as the one minimizing the differences between the EOF prediction and observations. This required a few iterations,

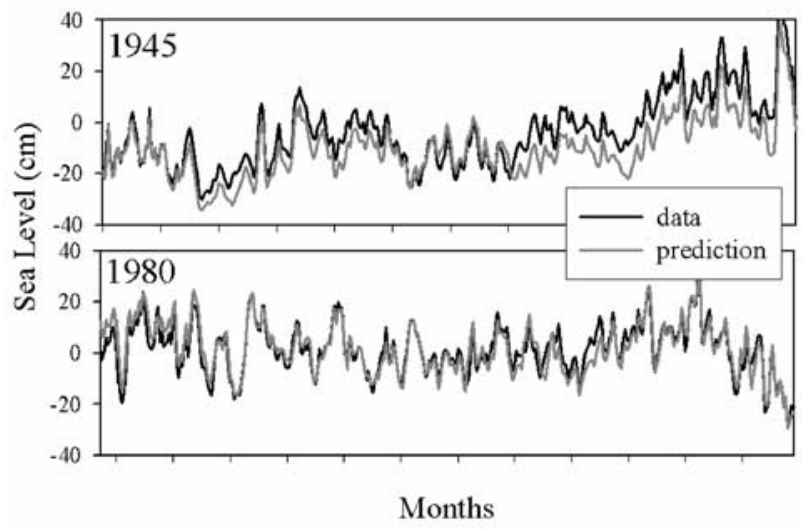

Figure 4. Comparison between observed (black lines) and EOF predicted (shaded lines) sea level for 2 years of the Coruña record: 1945 (before the detected reference jump) and 1980 (after the jump). 


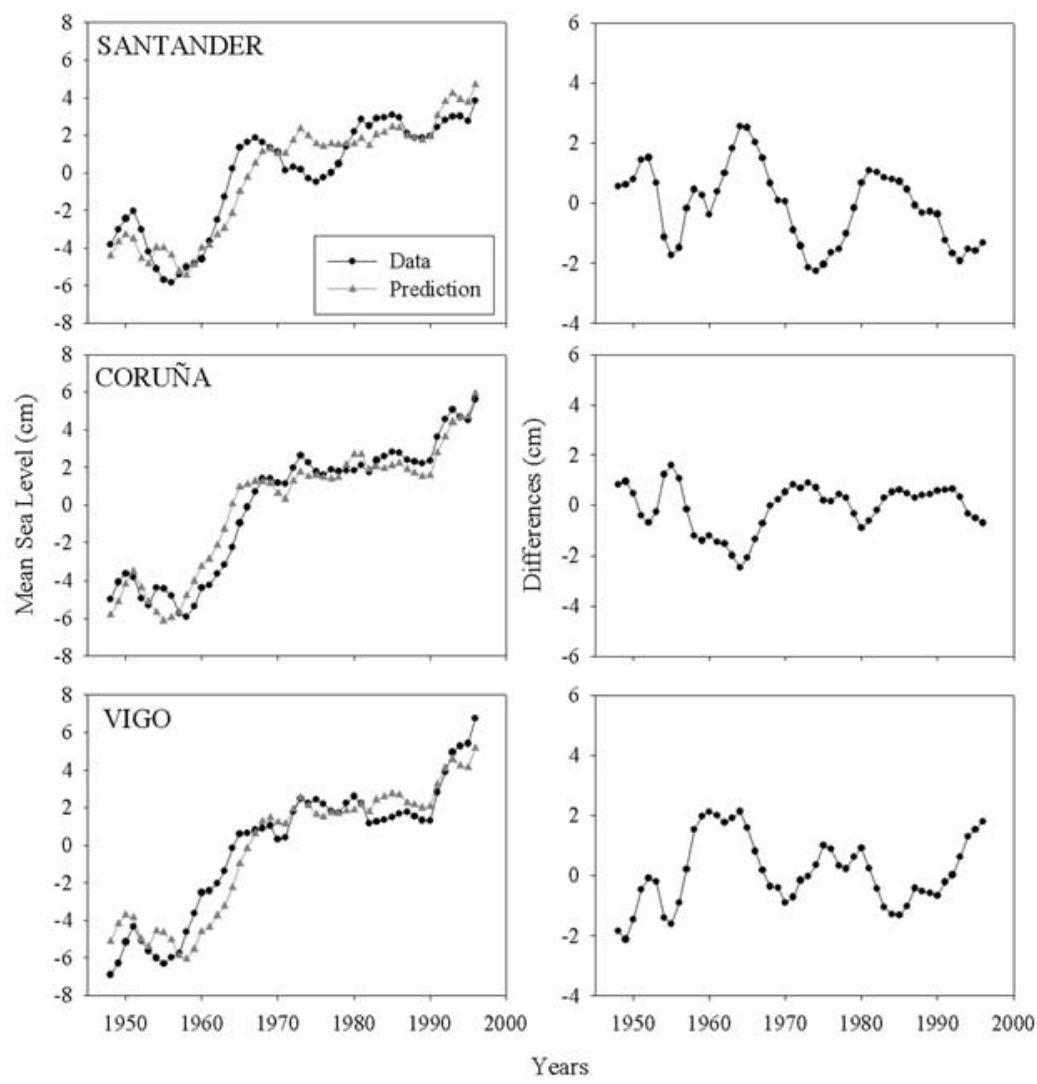

Figure 5. As for Figure 3, but using the corrected Coruña record.

since for each attempted correction the whole procedure (including the computation of EOFs) had to be repeated. Best results were obtained subtracting $4 \mathrm{~cm}$ from the whole period before the 1963 gap of the Coruña record. Results are shown in Figure 5: no clear jump is observed in the difference records, which now oscillate around zero within a maximum range of $\pm 2 \mathrm{~cm}$. This value can actually be taken as a lower limit for a jump to be detected (for the particular case of the three series studied in this work). The spatial patterns obtained for the new EOFs were very similar to those of Figure 2a, meaning that the timeaveraged sea-level behavior of each station relative to the others was not significantly affected by the jump.

\subsection{A Second Application of the EOF Analysis: Filling the Gaps of Time Series}

[35] Data gaps can have a significant impact on the computation of trends, especially if records are relatively short (as are the PdE records). After the correction of the Coruña record described above and before proceeding to fill the data gaps of the series, the capabilities of the method were tested in the following way. For a given station, a piece of record was withdrawn and considered for all effects as a data gap. The artificial gap was then predicted (or 'filled') following the procedure described above. Finally, the prediction for the artificial data gap was compared with the withdrawn observations.

[36] This experiment was carried out for each of the long series, taking 1-year-long artificial gaps. Best results were obtained using two EOFs, for which the bias/standard deviation of the differences between data and predictions were 2.32/4.66 cm for Santander, $-1.29 / 2.92 \mathrm{~cm}$ for Coruña, and $0.40 / 4.09 \mathrm{~cm}$ for Vigo. The fact that both the bias and the standard deviation are higher for Santander indicates that this station is submitted to somewhat distinct forcings with respect to Coruña and Vigo. The gaps of all IEO records were then filled using predictions based on two EOFs. The method was also applied to the PdE records spanning the last decade.

[37] The technique for filling data gaps was also useful for re-examining the differences between the two collocated records in Vigo. Monthly mean values of both records were now compared to the (monthly averaged) EOF prediction for years 2000 and 2001. Figure 6 shows that, as reported in section 2.3, the two records are rather similar except for year 2001. In particular, both closely follow the EOF predictions plotted for year 2000. During 2001, the IEO record departs significantly from the prediction. The presence of data gaps in the PdE record does not allow a full comparison, but the existing months show good agreement between observations and prediction. This points to the IEO record as the anomalous one, and therefore we decided to substitute year 2001 of the original IEO record with its EOF prediction (i.e., we considered year 2001 as a one-year data gap).

\section{Estimation of Trends From the Corrected Series}

[38] Interdecadal trends were recomputed for the corrected records (Table 2). After filling the gaps (including year 2001), the value obtained for Vigo shifted from 2.63 to $2.69 \mathrm{~mm} / \mathrm{yr}$. For Santander, the substitution of the 1996-2001 piece of the 

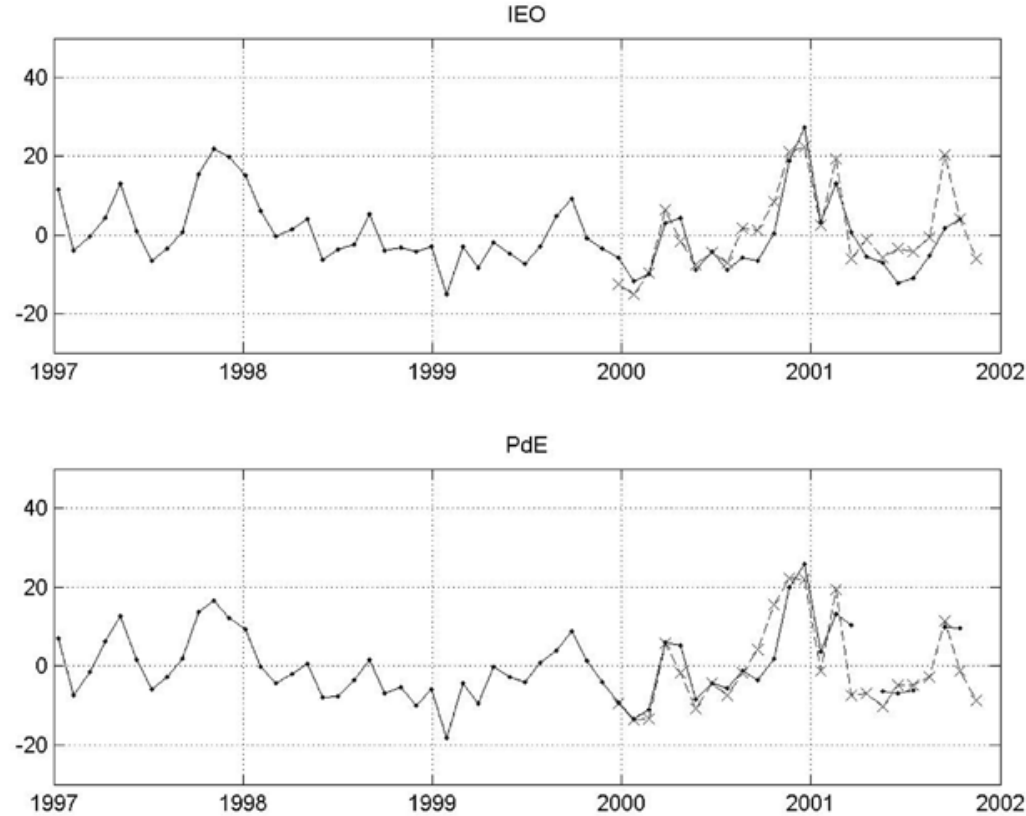

Figure 6. Monthly averaged sea level in Vigo for (top) the IEO record and (bottom) the PdE record. Black solid lines correspond to actual observations, and shaded dashed lines correspond to EOF predictions.

IEO record (responsible for the anomalously high trend of the last decade) by the PdE record resulted in a slightly smaller interdecadal trend: from $2.06 \mathrm{~mm} / \mathrm{yr}$ to $1.91 \mathrm{~mm} / \mathrm{yr}$. Filling the data gaps provided an additional small correction, the final trend being $1.85 \mathrm{~mm} / \mathrm{yr}$.

[39] In contrast to these small changes, the trend obtained for the Coruña record after the correction of the jump was almost $1 \mathrm{~mm} / \mathrm{yr}$ larger than for the original series: from 1.46 to $2.40 \mathrm{~mm} / \mathrm{yr}(2.38 \mathrm{~mm} / \mathrm{yr}$ after filling the data gaps $)$. The first obvious consequence is that the maximum difference between stations reduces from 1.16 to $0.84 \mathrm{~mm} / \mathrm{yr}(0.79 \mathrm{~mm} / \mathrm{yr}$ after the PGR correction). The new difference is still significantly larger than statistical errors, but the spatial pattern of the trend is now more consistent: The long IEO corrected series shows higher values for Atlantic stations than in the Gulf of Biscay, in agreement with the shape of the leading EOF (Figure 2a).

[40] The values obtained for these IEO stations are larger than previous results obtained by other authors [Douglas,
2001; Peltier, 2001a] at relatively close locations of the northeast Atlantic Ocean: $1.04 \mathrm{~mm} / \mathrm{yr}$ in Brest (Britanny, France), $1.45 \mathrm{~mm} / \mathrm{yr}$ in Newlyn (Great Britain), $1.89 \mathrm{~mm} / \mathrm{yr}$ in Cascais (western coast of Portugal), and $1.70 \mathrm{~mm} / \mathrm{yr}$ in Lagos (southern coast of Portugal). All the reported values are PGR-corrected. A possible reason for the differences is the distinct length of the records. While the IEO records cover the second half of the twentieth century, the length of the other reported series is of the order of 80 years, covering from the first decades of the twentieth century to the beginning of the 1990 decade. It is therefore important to estimate the sensitivity of trends with respect to the length of the records.

[41] In order to investigate the decadal variability of sea level, we computed the trend of the 10 -year periods centered on every year of the entire record (except for years before 1948 and after 1996, which are not central to a whole decade of data). Results reveal a marked variability, with values ranging from -15 to $+15 \mathrm{~mm} / \mathrm{yr}$ in Santander, from

Table 2. Observed and PGR-Corrected Sea-Level Trends Computed for the Corrected IEO (Interdecadal and Decadal) and PdE (Decadal) Series ${ }^{\mathrm{a}}$

\begin{tabular}{|c|c|c|c|c|c|}
\hline \multirow[b]{2}{*}{ Station } & \multirow[b]{2}{*}{$\begin{array}{c}\text { Post-Glacial } \\
\text { Rebound }\end{array}$} & \multicolumn{2}{|c|}{$1943-2001$} & \multicolumn{2}{|c|}{$1993-2001$} \\
\hline & & $\begin{array}{l}\text { Relative Sea- } \\
\text { Level Trend }\end{array}$ & $\begin{array}{l}\text { PGR-Corrected } \\
\text { Sea-Level Trend }\end{array}$ & $\begin{array}{l}\text { Relative Sea- } \\
\text { Level Trend }\end{array}$ & $\begin{array}{l}\text { PGR-Corrected } \\
\text { Sea-Level Trend }\end{array}$ \\
\hline IEO-Santander & -0.27 & $1.85 \pm 0.09$ & 2.12 & - & - \\
\hline IEO-Coruña & -0.13 & $2.38 \pm 0.09$ & 2.51 & $3.78 \pm 1.40$ & 3.91 \\
\hline IEO-Vigo & -0.22 & $2.69 \pm 0.09$ & 2.91 & $3.30 \pm 1.40$ & 3.52 \\
\hline PdE-Bilbao & -0.33 & & & $5.75 \pm 1.31$ & 6.08 \\
\hline PdE-Santander & -0.27 & & & $5.59 \pm 1.32$ & 5.86 \\
\hline PdE-Coruña & -0.13 & & & $3.94 \pm 1.38$ & 4.07 \\
\hline PdE-Vigo & -0.22 & & & $2.65 \pm 1.41$ & 2.87 \\
\hline
\end{tabular}

${ }^{\text {a}}$ PGR values provided by ICE4G model of Peltier [2001b] are also presented (negative values indicate land ascent).The uncertainty refers to the $90 \%$ confidence interval yielded by the bootstrap method. All values are in $\mathrm{mm} / \mathrm{yr}$. 

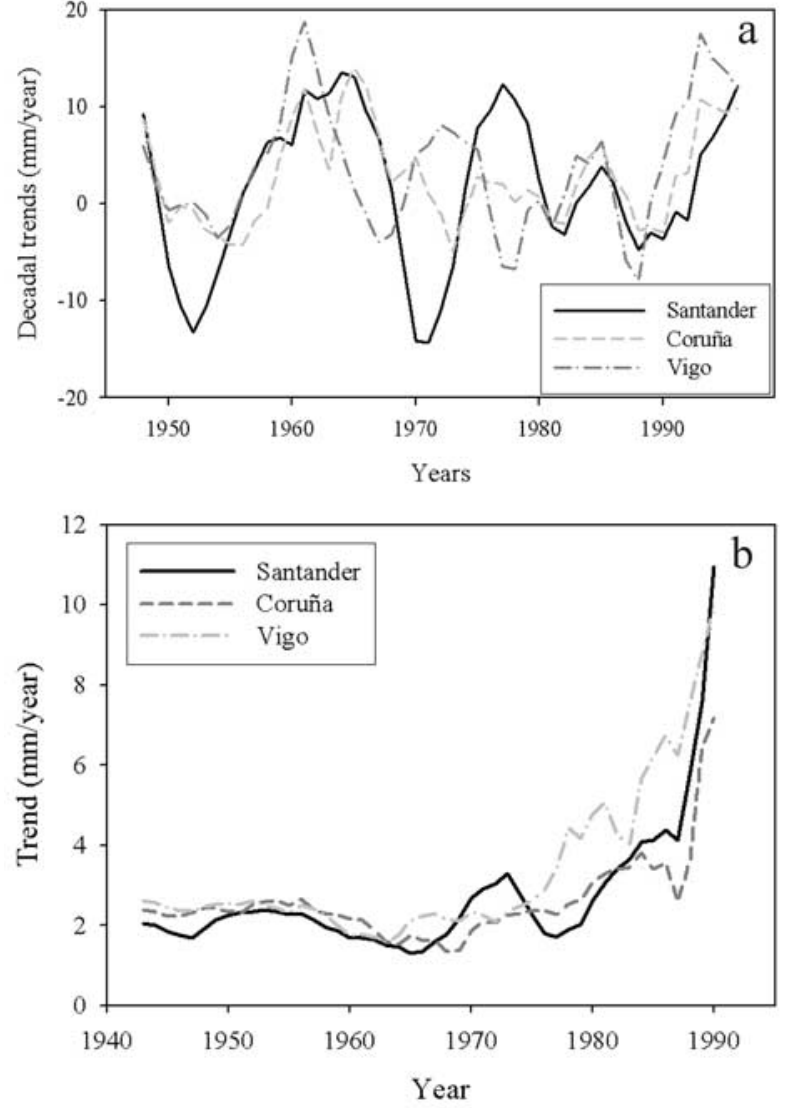

Figure 7. (a) Time evolution of decadal trends for the IEO time series. Values correspond to the linear trend of 10-year periods centered on each year (years before 1948 and after 1996 are not represented because they are not central to a whole decade of data). (b) Trends computed for the period between each year and the end of the records (2001). The last value is for 1991 in order to cover at least 10 years of data.
-5 to $+20 \mathrm{~mm} / \mathrm{yr}$ in Vigo, and from -5 to $+15 \mathrm{~mm} / \mathrm{yr}$ in Coruña (Figure 7a). It is worth noting, for instance, that decadal trends computed just before and around 1990 are clearly negative. This means that the significant sea-level rise observed during the 1990s actually followed a sea-level lowering that occurred during the $1980 \mathrm{~s}$. The overall result of the 2 decades is nevertheless positive: Sea level is presently higher than ever before, as shown in Figure 5. Summarizing, Figure 7a indicates the extent to which the computation of decadal trends can be misleading with respect to longer-term trends. Instead, it does not provide clear evidence for an acceleration of sea-level rise during the second half of the century.

[42] In a further attempt at estimating the sensitivity of trends with respect to the length of the records, we also computed the linear trend for the periods between each year and the end of the records (2001), starting in 1991 in order to cover at least 10 years of data. Figure $7 \mathrm{~b}$ shows that trends get more or less stable when at least 40 years of data are used. Because the records are only 58 years long, it is not easy to extrapolate the trends backward, but at first sight, there is no clear evidence that they would approach the lower values reported above for secular trends. Computing Figure $7 \mathrm{~b}$ the other way round (trends corresponding to periods between the beginning of the records and each year, not shown) revealed that the inclusion of the last decade does not result in a significant increase of interdecadal trends. Instead, further analysis indicated that the decade with a stronger impact is the 1960s, owing to the sharp sea-level increase observed in all records (see Figure 5). This increase, combined with the smaller trends registered during the first half of the twentieth century, would be mainly responsible for the differences with respect to secular trends obtained by other authors (though some small contribution due to the spatial variability of sea-level rise also cannot be discarded).

[43] Because the main source for decadal variability in the region is the NAO, we compared the annual wintermean sea level (averaged from December to March) of each series with the winter NAO index (Figure 8). The latter was

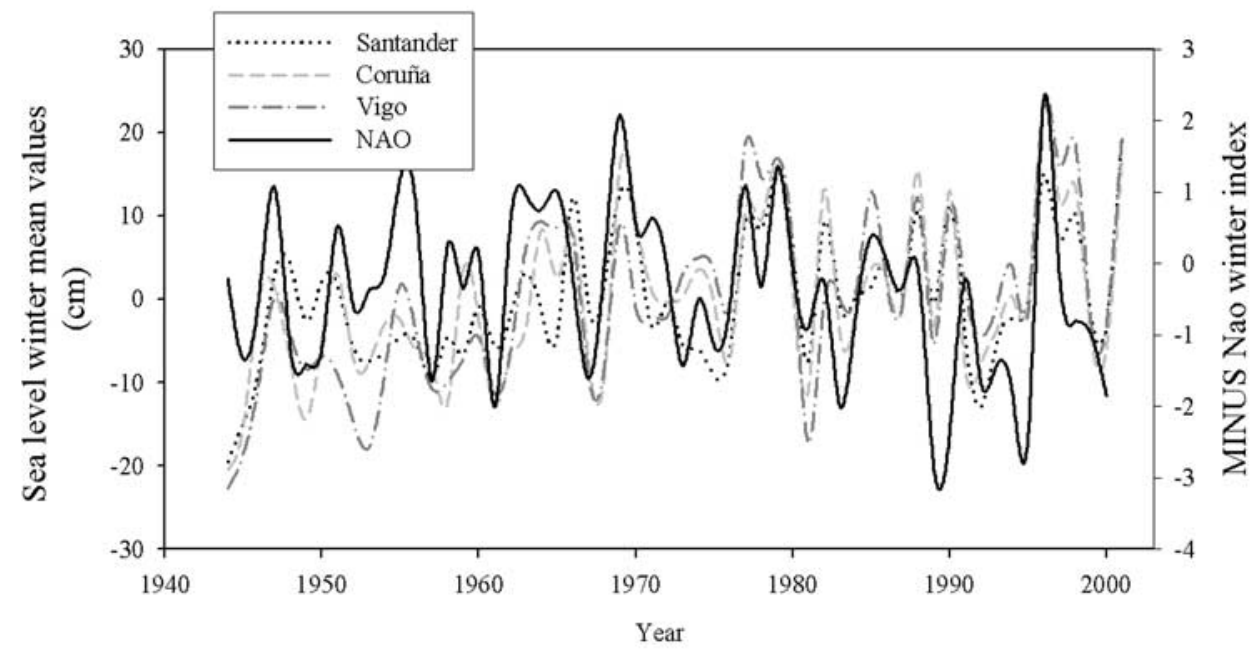

Figure 8. Winter mean (December-March) sea level at the three IEO stations (discontinuous lines) and the winter NAO index with sign changed (solid line). 
Table 3. PGR-Corrected Sea-Level Trends Computed for the Corrected IEO (Interdecadal and Decadal) and PdE (Decadal) Series ${ }^{\mathrm{a}}$

\begin{tabular}{|c|c|c|c|c|c|}
\hline \multirow[b]{2}{*}{ Station } & \multicolumn{2}{|c|}{$1943-2001$} & \multicolumn{3}{|c|}{$1993-2001$} \\
\hline & $\begin{array}{l}\text { PGR-Corrected } \\
\text { Sea-Level Trend }\end{array}$ & $\begin{array}{c}\text { Meteorological } \\
\text { Trend }^{\mathrm{b}}\end{array}$ & $\begin{array}{l}\text { PGR-Corrected } \\
\text { Sea-Level Trend }\end{array}$ & $\begin{array}{c}\text { Meteorological } \\
\text { Trend }\end{array}$ & $\begin{array}{c}\text { SST } \\
\text { Trend } \\
\end{array}$ \\
\hline IEO-Santander & 2.12 & -0.44 & & 0.73 & 0.0656 \\
\hline IEO-Coruña & 2.51 & -0.27 & 3.91 & 0.97 & 0.0193 \\
\hline IEO-Vigo & 2.91 & -0.21 & 3.52 & 1.55 & 0.0055 \\
\hline PdE-Bilbao & & & 6.08 & 0.73 & 0.0707 \\
\hline PdE-Santander & & & 5.86 & 0.73 & 0.0656 \\
\hline PdE-Coruña & & & 4.07 & 0.97 & 0.0193 \\
\hline PdE-Vigo & & & 2.87 & 1.55 & 0.0055 \\
\hline
\end{tabular}

${ }^{a}$ The meteorological trends have been evaluated from the HIPOCAS data set, and the temperature trends of the last decade have been obtained from the analysis of SST images. All values are in mm/yr except the temperature trends, which are in ${ }^{\circ} \mathrm{C} / \mathrm{yr}$.

${ }^{\mathrm{b}}$ The meteorological trends have been evaluated for the period $1958-2001$.

derived by the Climate Research Unit of the University of West Anglia, from sea-level atmospheric pressure measured in Iceland and Gibraltar (http://www.cru.uea.ac.uk/cru/data/ nao.htm). It is worth noting here that the study region is within the influence of the positive atmospheric pressure anomaly, so that a positive/negative NAO index implies higher-/lower-than-average atmospheric pressure over the region and, under the simple inverse barometer response assumption, lower-/higher-than average sea level.

[44] The plot shows a good visual coherence between winter-mean sea level and NAO index at a decadal scale, though it is not as good on an annual basis (correlations between each series and the NAO index are -0.36 for Santander, -0.43 for Coruña, and -0.37 for Vigo). In particular, it is worth noting that in 1989 the NAO index reaches the highest value $(>3)$ of the second half of the twentieth century, whereas in 1996 it reaches the lowest value $(<-2)$. This period coincides with a winter-mean sealevel rise that ranges from about $25 \mathrm{~cm}$ in Santander to more than $30 \mathrm{~cm}$ in Vigo (Figure 8). Conversely, from 1996 to 2000 the NAO index rises again, which translates in a winter-mean sea-level decrease that ranges from about $18 \mathrm{~cm}$ in Santander to about $28 \mathrm{~cm}$ in Vigo. This is in agreement with the results of Woolf et al. [2003], who found that Vigo is one of the European stations with a stronger response to the NAO index. These authors quantified the response of Atlantic stations in $40-60 \mathrm{~mm} / \mathrm{NAO}$ index, whereas for stations within the Gulf of Biscay the values were of the order of $20-40 \mathrm{~mm} / \mathrm{NAO}$ index. However, these values are not comparable to those inferred here, as they were obtained from a smoothed NAO index (apart from corresponding to the period 1977-2001).

[45] Trends were also computed for the filled PdE records and for the piece of the IEO records spanning the same period (except for Santander; see Table 2). Collocated records are now significantly more coherent than the raw records: They differ by $0.16 \mathrm{~mm} / \mathrm{yr}$ in Coruña and by 0.65 in Vigo (for the latter, the decadal trend shifted from 0.51 to $3.30 \mathrm{~mm} / \mathrm{yr}$ after the correction of year 2001). Moreover, the corrected trends show a well-defined spatial pattern along the northern Spanish coast: Absolute values are about $3 \mathrm{~mm} / \mathrm{yr}$ in Vigo, $4 \mathrm{~mm} / \mathrm{yr}$ in Coruña, almost $6 \mathrm{~mm} / \mathrm{yr}$ in Santander, and more than $6 \mathrm{~mm} / \mathrm{yr}$ in Bilbao. This pattern is opposite to that found for the interdecadal trends, which were higher for Atlantic stations than for the Gulf of Biscay (also shown in Table 2). Instead, it is in agreement with the results obtained for the last decade by other authors. For instance, Woolf et al. [2003] analyzed satellite altimetry data spanning a similar period (1992-2001) and found sea-level trends of about $1 \mathrm{~mm} / \mathrm{yr}$ in Vigo and $3 \mathrm{~mm} / \mathrm{yr}$ in Bilbao.

\section{Different Physical Contributions to Interdecadal Trends}

[46] The contribution of the meteorological forcing to sea-level trends was quantified using the HIPOCAS-HAMSOM model. This goes beyond a simple inverted barometer response, since atmospheric pressure and wind are both included explicitly as forcing terms in the equations of motion. Meteorologically induced sea-level trends were first estimated in the vicinity of the long sea-level series for the 44 years (1958-2001) covered by the HAMSON reanalysis. Although this period does not exactly match the one covered by sea-level records, it is expected to give a reasonable estimate of the meteorological contribution during the second half of the twentieth century.

[47] Results show negative trends in the vicinity of the three stations (see Table 3). Since the meteorological contribution is significantly smaller than the total variability of sea level (and both series have approximately the same length), the statistical errors associated with the meteorological contribution would be smaller than the $0.09 \mathrm{~mm} / \mathrm{yr}$ obtained for the observed series and therefore would not play a meaningful role in the interpretation of results. Negative trends indicate that meteorology would be acting in the sense of reducing sea-level rise in the region. This is consistent with the slightly positive trend of the winter NAO index during the second half of the twentieth century (see Figure 8), although this result must be considered cautiously as the contribution of the other seasons are not included in the winter NAO trend.

[48] The spatial pattern of meteorologically induced trends is in agreement with the pattern of sea-level: smaller values correspond to Santander $(-0.44 \mathrm{~mm} / \mathrm{yr})$, followed by Coruña $(-0.27 \mathrm{~mm} / \mathrm{yr})$ and Vigo $(-0.21 \mathrm{~mm} / \mathrm{yr})$. In fact, Figure 8 by itself suggests that winter sea-level trends resemble the pattern of total trends (higher for Atlantic stations than within the Gulf of Biscay). When the meteorological contribution is subtracted, the differences between station sea-level trends is reduced from 0.79 to $0.56 \mathrm{~mm} / \mathrm{yr}$. That is, the differential meteorological trend accounts for about a third of the sea-level trend differences.

[49] The meteorological contribution was also estimated for the period 1993-2001 (Table 3). Conversely to inter- 
decadal meteorologically induced trends, results are positive for all stations, which is in agreement with the overall NAO negative trend of the last decade (Figure 8). Instead, the spatial pattern is in the same sense than meteorologically induced interdecadal trends: higher for Atlantic stations $(1.55 \mathrm{~mm} / \mathrm{yr}$ in Vigo) than for stations located within the Gulf of Biscay $(0.73 \mathrm{~mm} / \mathrm{yr}$ in Bilbao and Santander). This is again in agreement with Woolf et al.'s [2003] statement that Atlantic stations respond to the NAO variability better than the other stations.

[50] The spatial pattern of the last decade sea-level trends (higher in the Gulf of Biscay than in the Atlantic coast) is opposite to that of sea-level interdecadal trends and, therefore, also opposite to meteorologically induced trends. Since the winter-mean sea-level evolution follows the same pattern as the meteorological forcing (Figure 8), it then follows that the nonmeteorological contribution must play a key role during the other seasons. Also, of course, its spatial pattern must be opposite to the winter effects of atmospheric pressure and wind.

[51] Once the meteorological contribution is removed, the remaining sea-level trends range from slightly more than $1 \mathrm{~mm} / \mathrm{yr}$ in Vigo to more than $5 \mathrm{~mm} / \mathrm{yr}$ in Santander and Bilbao. Therefore, although the meteorological forcing explains a significant part of the interannual sea-level variability, it is only 10 to $20 \%$ of (and in opposite sense to) the long-term sea-level rise (Table 3). The dominant processes must therefore be the water volume expansion derived from an increase of the heat content of the ocean [Levitus et al., 2000] and/or mass changes due to melting of the continental ice [Miller and Douglas, 2004]. In order to check the first contribution, the mean North Atlantic temperature derived by Levitus et al. [2000] for the second half of the twentieth century was compared with the 10-year mean sea level shown in Figure 5. The comparison (Figure 9) shows clear similarities but also discrepancies. The most apparent difference is the time lag between the sharp increases observed in both signals. The increase in temperature is actually a worldwide feature [see Levitus et al., 2000] that started by the middle 1950s. However, while the three sea-level records reach local maxima by the late $1960 \mathrm{~s}$, the mean North Atlantic temperature continues increasing until the late 1970s. This indicates that the increase of the heat contents would have occurred earlier in the study region than in other regions of the North Atlantic Ocean.

[52] Assuming that the described thermosteric effect explains an important part of the observed sea-level rise, the question then arises as to whether the differences between stations can also be attributed to spatial differences in the temperature increase or, instead, are due to changes in the coastal circulation or to unaccounted effects such as local tectonics. The first hypothesis can hardly be checked for the long records, since historical temperature data sets are too poor to discriminate between such close locations. However, some attempt can be made for the last decade, during which satellite SST data were available.

[53] We followed Garcia-Lafuente et al. [2004], who compared SST data with collocated dynamic height observations for the period 1993-2001. Despite the fact that dynamic height is more representative of the water volume than SST, observations are too sparse in space and time to

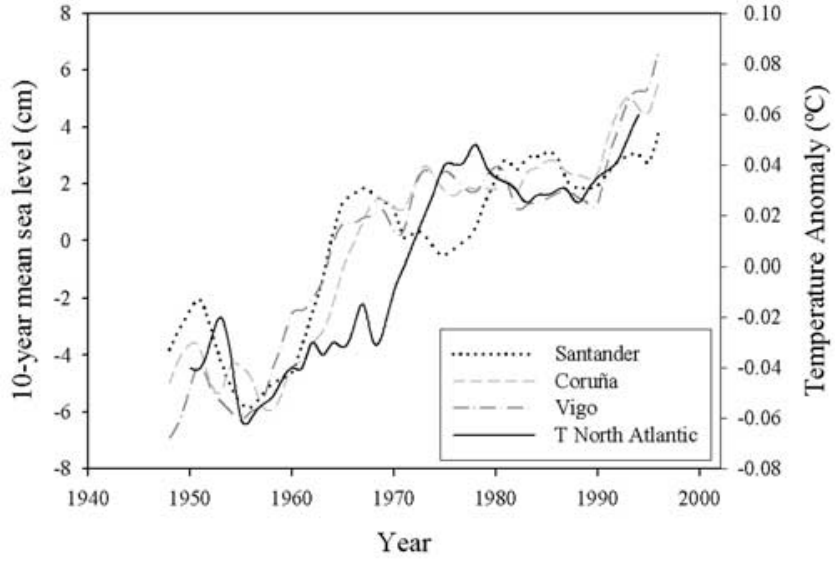

Figure 9. Ten-year moving average of sea level recorded at the three IEO stations (discontinuous lines) and mean temperature of the North Atlantic ocean compiled by Levitus et al. [2000] (solid line). (The latter was obtained from the digitization of the plot published on the web site http://www.sciencemag.org/feature/data/1046907.shl).

infer a reliable location-dependent interannual variability. However, Garcia-Lafuente et al. [2004] found a direct correlation between the annual cycles of SST and dynamic height, which suggests that the first can be used as an indicator of the ocean heat contents in the region. Monthly mean SST was then averaged over small $\left(20 \times 20 \mathrm{~km}^{2}\right)$ areas in the vicinity of each station and decadal trends were computed from the resulting series. Results show a clear spatial pattern that agrees with that obtained for sea level (see Table 3). Namely, SST trends range from about $0.005^{\circ} \mathrm{C} / \mathrm{yr}$ in Vigo to more than $0.070^{\circ} \mathrm{C} / \mathrm{yr}$ in Bilbao (for the same period, the increase in the North Atlantic mean temperature is about $0.006^{\circ} \mathrm{C} / \mathrm{yr}$, according to Levitus et al. [2000]). It then follows that, at least for the last decade, the station differences between sea-level trends could be mostly explained in terms of spatial differences in the evolution of the ocean temperature.

\section{Conclusions}

[54] The consistency study applied to tide-gauge data has been crucial for the determination of reliable sea-level trends. The EOF analysis has allowed the detection and correction of a jump of $4 \mathrm{~cm}$ in the reference level of the Coruña record that distorted the interdecadal trend at that station. Also, data gaps were filled, though for the long series they only had a minor impact on the computed trends. Comparison with shorter (less than 1 decade) collocated and nearby records has also contributed to improving the consistency of the records.

[55] Trends computed from the corrected records have revealed a net sea-level rise (observed rise corrected for the PGR) of $2.12 \mathrm{~mm} / \mathrm{yr}$ in Santander, $2.51 \mathrm{~mm} / \mathrm{yr}$ in Coruña, and $2.91 \mathrm{~mm} / \mathrm{yr}$ in Vigo during the period 1943-2001. The $90 \%$ confidence interval of these results has been estimated in about $0.09 \mathrm{~mm} / \mathrm{yr}$ by means of a bootstrap method. Trends are on average $1 \mathrm{~mm} / \mathrm{yr}$ larger than those computed from series recorded in nearby locations and covering most of the twentieth century. This has been interpreted in terms 
of an enhanced sea-level rise during the second half of the twentieth century with respect to the first half.

[56] Regarding the physical mechanisms that are responsible for the observed sea-level rise, a similar evolution has been found between the North Atlantic mean temperature (derived by Levitus et al. [2000]) and sealevel observations. The increase of the ocean heat content has therefore been pointed out as responsible for part of the observed sea-level rise, in agreement with Levitus et al. [2000] and Church et al. [2001]. Since the impact of the ocean warming on sea-level rise was not quantified, other mechanisms such as the ocean mass increase may also have contributed to the observed trends. Instead, the meteorological contribution shows negative trends at the three stations. That is, the meteorological forcing would act in the sense of slightly slowing the sea-level rise due to the thermosteric contribution.

[57] The spatial pattern of meteorologically induced trends is in the same sense as the pattern of PGR-corrected sea-level trends (higher for Atlantic stations that in the Gulf of Biscay). More precisely, the differential meteorological forcing accounts for about a third of the differences between station PGR-corrected sea-level trends. The remaining differences are likely due to the spatial variability of the observed long-term increase in the ocean heat contents. However, this has only been proved for the last decade, so that an eventual contribution from local changes in the coastal circulation cannot be discarded.

[58] The high sea-level trends obtained for the last decade suggests an acceleration of the local long-term sea-level rise. However, some caution is necessary to interpret the origin of this possible acceleration because meteorologically induced trends are positive, a fact that is in agreement with the overall NAO negative trend of the last decade. If the meteorological contribution is removed from the PGRcorrected sea-level trend in order to highlight the thermosteric and ice-melting contributions, the trends of the long and last-decade series are brought closer. Even so, trends in the easternmost stations (Bilbao, Santander) are noticeably higher than the values computed for the long period, which could be a consequence of an enhanced seawater heating in this area during this decade. The relatively large SST trends near these stations (Table 3) would support this hypothesis. Curiously, the spatial pattern of PGR-corrected sea-level trends is opposite to that of the meteorological contribution during the last decade, while spatial pattern of SST trends in the vicinity of the tide gauge stations is in the same sense as that observed for sea level. This indicates that the thermosteric contribution not only would be a major responsible for the observed sea-level rise, but also could explain the differences between the different station sea-level trends.

\section{Appendix A}

[59] A major result of EOF analysis is the decomposition of the series in orthogonal modes based on the criterion of maximum variability. First, the eigenvectors and eigenvalues of the (real, symmetric) covariance matrix were computed. The eigenvectors have one component for each series and provide the spatial pattern of the mode. The variance fraction accounted for by each mode is given by the ratio of the corresponding eigenvalue relative to the sum of all of them (which is itself equal to the trace of the covariance matrix).

[60] Hence each record can be decomposed in terms of the eigenvectors and their corresponding temporal amplitudes,

$$
\eta(x, t)=\sum_{i=1}^{N} A_{i}(t) E^{i}(x),
$$

where $\eta$ is the sea-level elevation measured at location $x$ and time $t, A_{i}(t)$ is the temporal amplitude of the $i$ th mode, and $E^{i}(x)$ is the $x$ component of the $i$ th eigenvector. $N$ is equal to the number of records. Only the time periods with valid data at all the records can be used to compute the covariance matrix. For these periods, the mode amplitudes $A_{i}(t)$ can be easily computed as the scalar product between the vector of sea-level observations at time $t$ (one component for each station) and the $i$-eigenvector.

[61] However, once the eigenvectors have been determined, the leading amplitudes can also be estimated for time periods for which only a subset of $M$ stations out of the total number $N$ is available. A first way would be imposing the condition that the prediction given by the leading $M$ EOFs matches the $M$ existing observations. This leads to a linear equation system in $M$ unknowns that can be easily solved. However, Haney et al. [1995] suggest fitting the amplitudes in a sequential way: First, the amplitude of the leading EOF is computed imposing that the difference between the prediction provided by this mode and the $M$ observations is minimized. For subsequent modes, the minimization is applied to the difference between the prediction of each mode and the residual signal resulting from subtracting the predictions of previous modes to observations. Unlike the previous method, this one allows fit of the whole set of $N$ amplitudes. Sea level can then be obtained at every station by means of (1), and in particular at the $N-M$ sites that were not used for the amplitude determination.

[62] The physics underlying this concept is that the largescale pattern accounted for by the leading modes (described in section 3.1) can be determined from a subset of records and then propagated to the others with a differential factor given by the component of the eigenvector at each particular site. This cannot be extended to the last modes, which usually account for local phenomena, and therefore only a limited number of them are usually considered to "predict" the signal at sites with missing data.

[63] Acknowledgments. This study was supported by Puertos del Estado through a research contract established with the University of Málaga and the University of the Balearic Islands ("Convenio de colaboración para el desarrollo y aplicación de técnicas de análisis de series temporales de nivel del mar"'). The sea-level series were kindly provided by María Jesús García, from the Instituto Español de Oceanografía. The modeled sea-level trend was obtained from the EU HIPOCAS project (contract EKV2-CT-1999-00038). The authors are also grateful to Juan José Egozcue for his valuable comments on this work. Finally, Marta Marcos acknowledges a fellowship funded by the EU ESEAS-RI project (contract EVR1-CT-2002-40025)

\section{References}

Álvarez-Fanjul, E., B. Pérez, and I. Rodríguez (1997), A description of the tides in the Eastern North Atlantic, Prog. Oceanogr., 40, 217-244.

Álvarez-Fanjul, E., B. Pérez, and I. Rodríguez (2001), NIVMAR: A stormsurge forecasting system for Spanish waters, Sci. Mar., 60, 145-154.

Antonov, J. I., S. Levitus, and T. Boyer (2002), Steric sea level variations during 1957-1994: Importance of salinity, J. Geophys. Res., 107(C12), 8013, doi:10.1029/2001JC000964. 
Cabanes, C., A. Cazenave, and C. Le Provost (2001), Sea level rise during the past 40 years determined from satellite and in situ observations, Science, 294, 840-842.

Church, J. A., J. M. Gregory, P. Huybrechts, M. Kuhn, K. Lambeck, M. T. Nhuan, D. Qin, and P. L. Woodworth (2001), Changes in sea level, in Intergovernmental Panel on Climate Change, Third Assessment Report chap. 11, pp. 639-694, Cambridge Univ. Press, New York.

Douglas, B. C. (1991), Global sea level rise, J. Geophys. Res., 96(C4), $6981-6992$.

Douglas, B. C. (1997), Global sea level rise: A redetermination, Surv. Geophys., 18, 279-292.

Douglas, B. C. (2001), Sea level change in the era of the recording tide gauge, in Sea Level Rise: History and Consequences, edited by B. C. Douglas, M. S. Kearney, and S. P. Leatherman, pp. 37-64, Elsevier, New York.

Efron, B., and R. J. Tibshirani (1993), An Introduction to the Bootstrap, CRC Press, Boca Raton, Fla.

García-Lafuente, J., J. Del Río, E. Álvarez-Fanjul, D. Gomis, and J. Delgado (2004), Some aspects of the seasonal sea level variations around Spain J. Geophys. Res., 109(C9), C09008, doi:10.1029/2003JC002070.

Guedes Soares, C., J. C. Carretero Albiach, R. Weisse, and E. ÁlvarezFanjul (2002), A 40 years hindcast of wind, sea level and waves in European waters, paper presented at 21 st International Conference on Offshore Mechanics and Arctic Engineering, Am. Soc. of Mech. Eng., Oslo.

Haney, R. L., R. A. Hale, and C. A. Collins (1995), Estimating subpycnocline density fluctuations in the California Current region from upper ocean observations, J. Atmos. Oceanic Technol., 12, 550-566.

Levitus, S., J. I. Antonov, T. P. Boyer, and C. Stephens (2000), Warming of the World Ocean, Science, 287, 2225-2229.

Miller, L., and B. C. Douglas (2004), Mass and volume contributions to twentieth-century global sea level rise, Nature, 428, 406-409.

Nerem, R. S. (1999), Measuring very low frequency sea level variations using satellite altimetric data, Global Planet. Change, 20, 157-171.

Nicholls, R. J., and S. P. Leatherman (1994), Global sea level rise, in As Climate Changes: Potential Impacts and Implications, edited by K. Strzepek and J. B. Smith, pp. 92-123, Cambridge Univ. Press, New York.
Parker, B. B., R. E. Cheney, and W. E. Carter (1992), NOAA Global Sea Level Program, Sea Technol., 33(6), 55-62.

Peltier, W. R. (2001a), Global glacial isostatic adjustment and modern instrumental records of relative sea level history, in Sea Level Rise: History and Consequences, edited by B. C. Douglas, M. S. Kearney, and S. P. Leatherman, pp. 65-95, Elsevier, New York.

Peltier, W. R. (2001b), Glacial isostatic adjustment corrections, in Sea Level Rise: History and Consequences, edited by B. C. Douglas, M. S. Kearney, and S. P. Leatherman, pp. 177-178, Elsevier, New York.

Wakelin, S. L., P. L. Woodworth, R. A. Flather, and J. A. Williams (2003), Sea level dependence on the NAO over the NW European Continental Shelf, Geophys. Res. Lett., 30(7), 1403, doi:10.1029/2003GL017041.

Willis, J. K., D. Roemmich, and B. Cornuelle (2003), Combining altimetric height with broadscale profile data to estimate steric height, heat storage, subsurface temperature, and sea-surface temperature variability, J. Geophys. Res., 108(C9), 3292, doi:10.1029/2002JC001755.

Woodworth, P. L., and R. Player (2003), The Permanent Service for Mean Sea Level: An update to the 21 st century, J. Coastal Res., 19(2), 287295

Woolf, D., A. Shaw, and M. Tsimplis (2003), The influence of the North Atlantic Oscillation on sea level variability in the North Atlantic region, Global Atmos. Ocean Syst., 9(4), 145-167.

E. Álvarez-Fanjul and B. Pérez, Área del Medio Físico, Puertos del Estado, Av. Del Partenón 10, E-28042 Madrid, Spain. (enrique@puertos.es; bego@puertos.es)

J. García-Lafuente, ETSI Telecomunicación, Departamento de Física Aplicada II, Universidad de Málaga, Campus de Teatinos, E-29071, Malaga, Spain. (glafuente@ctima.uma.es)

D. Gomis, M. Marcos, and S. Monserrat, Grup d'Oceanografia Interdisciplinar, Instituto Mediterraneo de Estudios Avanzados (UIBCSIC), C/Miquel Marquès 21, Esporles, E-07190, Mallorca, Spain. (marta.marcos@uib.es) 